\title{
Children's exposure to passive smoking in England since the 1980s: cotinine evidence from population surveys
}

\author{
Martin J Jarvis, Eileen Goddard, Vanessa Higgins, Colin Feyerabend, Andrew Bryant, Derek G Cook
}

\begin{abstract}
Objective To determine whether children's exposure to passive smoking has changed since the late 1980s. Design Cross sectional surveys of nationally representative samples of secondary school children carried out between 1988 and 1998 by Office for National Statistics.

Setting England.

Subjects Secondary school children aged 11-15. Main outcome measures Salivary cotinine concentrations in non-smoking children.

Results Cotinine concentrations in all non-smoking children almost halved between 1988 and 1998, from a geometric mean of 0.96 (95\% confidence interval 0.83 to 1.11$) \mathrm{ng} / \mathrm{ml}$ in 1988 to 0.52 (0.43 to 0.62 ) $\mathrm{ng} / \mathrm{ml}$ in 1998 . This reduction was largely due to reductions in exposure in children from non-smoking households and to decreases in the percentage of parents who smoked. Children living with mothers or fathers who smoked experienced little reduction in exposure.

Conclusions Exposure to passive smoking among children in England has approximately halved since the late 1980s. This reduction is partly explained by the fall in the percentage of both mothers and fathers who smoke and is also likely to reflect reductions of smoking in public places. However, there is only limited evidence that children from smoking households have experienced a reduction in exposure through parents' avoidance of smoking in their presence.
\end{abstract}

\section{Introduction}

The past decade has seen increasing restrictions on smoking in public places. Many workplaces in Britain have introduced smoking policies, and smoking has been banned on buses and the underground and in banks cinemas, post offices, and shops. Smoking in the home is less easily regulated. Much of the public health burden from passive smoking falls on children in the home, with clear evidence of causal effects for several diseases. ${ }^{1}$ There are reports from the United States and elsewhere of adult smokers, while not quitting smoking, implementing smoking bans in their homes. $^{2-5}$ The impact of this on children's measured exposure has not been established.

We here report cotinine concentrations in children measured during school based surveys carried out since 1988. We consider concentrations in children with non-smoking parents as an indicator of influences from broad trends in society, and we examine whether there is evidence for a decline in exposure among children with smoking parents.

\section{Subjects and methods}

Data were drawn from the regular national surveys of smoking in secondary schoolchildren aged 11-15 con- ducted by the Office for National Statistics. Since 1988 these have incorporated measures of saliva cotinine concentration in a random half of the schools surveyed. Full details of the survey methodology, which remained substantially unchanged over the period we consider, are given in published reports. ${ }^{6-12}$

The children we included for study were self reported non-smokers (including those who never smoked, those who had tried smoking, and former smokers) who also reported not smoking in a diary covering the previous seven days. To exclude children who denied their smoking, we restricted our study to those with cotinine concentrations below $15 \mathrm{ng} / \mathrm{ml}$, a suggested cutoff point for active smoking. ${ }^{13}$ Parental smoking was categorised as non-smoking household (neither parent smokes or lone non-smoking parent), only father smokes, only mother smokes, both parents smoke. Parental smoking was not reported in the 1998 survey.

Cotinine concentrations-Cotinine was assayed by gas chromatography with a detection limit of $100 \mathrm{pg} / \mathrm{ml} .^{14}$ To check for drift in the assay over time, in 1994 we reanalysed 25 samples gathered and analysed in 1990. The means were identical $(2.4 \mathrm{ng} / \mathrm{ml})$, and the Pearson correlation was high $(r=0.99)$.

Statistical analysis-Since the distribution of cotinine concentrations in non-smokers is positively skewed, we subjected the data to logarithmic transformation, first assigning a value of 0.05 to undetectable concentrations. We report geometric mean concentrations and their $95 \%$ confidence intervals. We allowed for the clustered, school based sampling frame by fitting school as a random effect in the "Mixed" procedure in SAS. All trends were tested by fitting year as a linear trend.

\section{Results in parents}

Table 1 shows the reported prevalence of parental cigarette smoking. The percentage of children living in nonsmoking households rose from $48 \%$ in 1988 to $57 \%$ in 1994 but declined in 1996 to $55 \%$, reflecting the increased prevalence of smoking in younger adults registered in the general household survey for that year. ${ }^{15}$

Figure 1 shows cotinine concentrations in all nonsmoking children, irrespective of parental smoking

Table 1 Prevalence of parental cigarette smoking reported by schoolchildren aged 11-15 in England

\begin{tabular}{lccc} 
& \multicolumn{3}{c}{$\%$ of households } \\
\cline { 2 - 4 } Year of survey & Non-smoking & Father smokes & Mother smokes \\
\hline $1988(n=1179)$ & 47.6 & 38.5 & 32.1 \\
\hline $1990(n=1219)$ & 50.1 & 36.1 & 31.7 \\
\hline $1992(n=2730)$ & 55.6 & 31.1 & 27.5 \\
\hline $1993(n=647)$ & 60.3 & 26.9 & 25.2 \\
\hline $1994(n=1100)$ & 56.8 & 30.3 & 25.8 \\
\hline $1996(n=576)$ & 54.5 & 28.1 & 29.2 \\
\hline
\end{tabular}

ICRF Health Behaviour Unit, Department of Epidemiology and Public Health, University College London, London WC1E 6BT

Martin JJarvis professor of health psychology

Office for National Statistics,

Drummond Gate, London

SW1V 2QQ

Eileen Goddard principal survey researcher

Vanessa Higgins survey researcher

Medical Toxicology Unit, New Cross Hospital, London SE14 5ER

Colin Feyerabend Andrew Bryant senior analyst

Department of Public Health

Sciences, St George's Hospital Medical School, London SW17 0RE Derek G Cook professor of epidemiology Correspondence to: MJ Jarvis martin.jarvis@ ucl.ac.uk

BMJ 2000;321:343-5 principal biochemist 


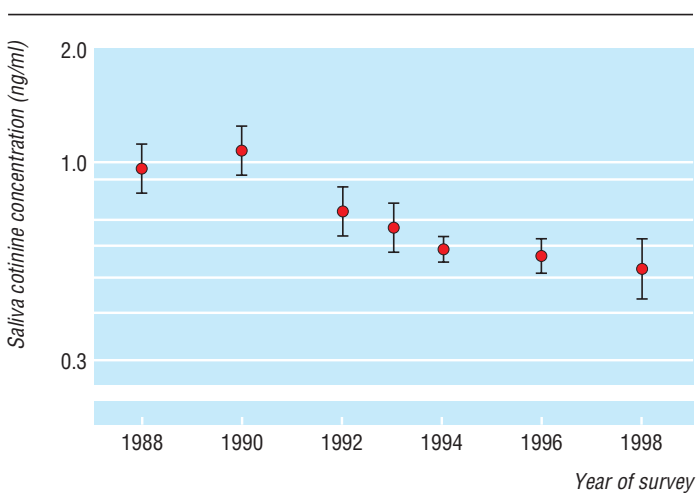

Fig 1 Trends in exposure to environmental tobacco smoke in schoolchildren in England from 1988 to 1998, as shown by salivary cotinine concentrations in all non-smoking children. Values are geometric means (95\% confidence intervals)

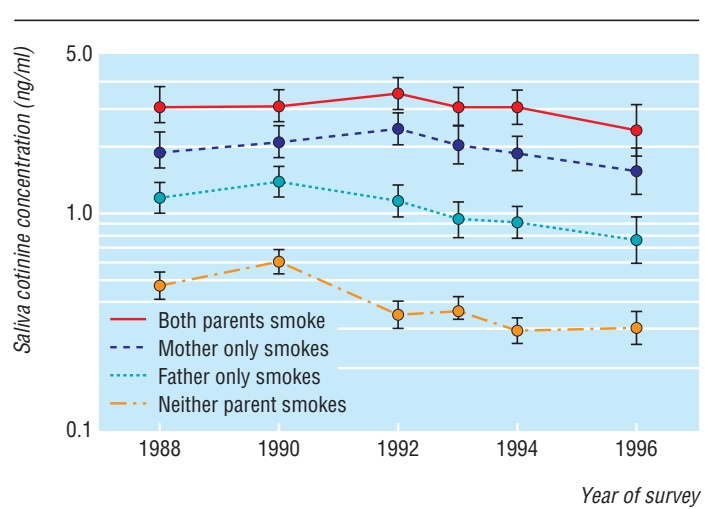

Fig 2 Trends in exposure to environmental tobacco smoke in schoolchildren in England from 1988 to 1998 by parental smoking habits, as shown by salivary cotinine concentrations in non-smoking children. Values are geometric means (95\% confidence intervals)

habits. The geometric mean approximately halved between 1988 and 1998, from $0.96 \mathrm{ng} / \mathrm{ml}$ to 0.52 $\mathrm{ng} / \mathrm{ml}$ (table 2 ), and the linear trend across years was highly significant $(\mathrm{P}<0.0001)$.

Cotinine concentrations in children from nonsmoking homes provide the best guide to trends in passive smoking in society generally, since any exposure to smoke presumably occurs largely outside the home. Concentrations declined significantly between 1988 and 1996 , from a geometric mean of $0.47 \mathrm{ng} / \mathrm{ml}$ to 0.28 $\mathrm{ng} / \mathrm{ml}(\mathrm{P}<0.0001)$ (see table 2 and fig 2$)$.

Changes over time in cotinine concentrations in children with parents who smoked were less marked than in children from non-smoking homes (table 2 and fig 2). Concentrations in children whose father alone smoked showed a significant decline over time $(\mathrm{P}<0.0001)$, whereas changes in concentrations in children whose mother alone smoked or whose mother and father both smoked were of borderline significance $(\mathrm{P}=0.04$ and $\mathrm{P}=0.089$ respectively).

\section{Discussion}

These results show a substantial decline in children's exposure to passive smoking in England since the late 1980s. On average, measured cotinine concentrations declined by almost a half between 1988 and 1998. The possibility that the findings could be an artefact explained by drift over time in the laboratory cotinine assay was ruled out by the almost identical results obtained from repeat assays of specimens from earlier years.

Changes in children's exposure to other people's tobacco smoke could be due to several factors. Among these, the most important is parental smoking. Previous work has shown that this is the main influence on children's cotinine concentrations and that exposure outside the home is quantitatively less important, especially in children aged under 16 years. ${ }^{16}{ }^{17}$ Our results confirm this. Reductions in the prevalence of parental smoking have been an important factor driving the reduction in the population burden of passive smoking in children.

Children's exposure to smoke is also influenced by the extent of smoking in the community they live in-for example, smoking in friends' homes, among visitors to their own homes, and in public places. We did not have direct information about such exposures. However, the continuing reductions in cotinine concentrations in children living in non-smoking households suggest that changes in society have led to an overall less smoky environment.

We found only small declines in exposure among children with smoking parents. Some decline would be expected from the reduction in community smoking in general. We do not know to what extent smoking parents in England have adopted policies to protect their children from exposure to tobacco smoke similar to those reported in other countries, ${ }^{2-5}$ but certainly the impact of any such measures is hard to detect at the population level. Testing the effectiveness of such policies would require more detailed and explicit quantitative evaluation.

\section{Conclusions}

Children's exposure to environmental tobacco smoke has declined substantially in England over the past decade. This has been due both to reductions in the prevalence smoking in young adults with children and

Table 2 Saliva cotinine concentrations ( $\mathrm{ng} / \mathrm{ml})$ in non-smoking children aged 11-15 in England by parental smoking

\begin{tabular}{lcccccc} 
& Mean age & \multicolumn{5}{c}{ Geometric mean $\mathbf{( 9 5 \% ~ C l ) ~ s a l i v a ~ c o t i n i n e ~ c o n c e n t r a t i o n ~ ( n g / m l ) ~}$} \\
\cline { 3 - 7 } Year of survey & (years) & Non-smoking parents & Only father smokes & Only mother smokes & Both parents smoke & Overall \\
\hline $1988(n=1228)$ & 13.6 & $0.47(0.42$ to 0.54$)$ & $1.15(0.98$ to 1.35$)$ & $1.91(1.59$ to 2.30$)$ & $3.08(2.60$ to 3.64$)$ & $0.96(0.83$ to 1.11$)$ \\
\hline $1990(n=1263)$ & 13.4 & $0.60(0.53$ to 0.67$)$ & $1.36(1.17$ to 1.58$)$ & $2.08(1.77$ to 2.45$)$ & $3.01(2.59$ to 3.50$)$ & $1.06(0.92$ to 1.23$)$ \\
\hline $1992(n=1334)$ & 13.4 & $0.34(0.30$ to 0.39$)$ & $1.10(0.93$ to 1.29$)$ & $2.34(1.94$ to 2.82$)$ & $3.33(2.78$ to 3.98$)$ & $0.74(0.63$ to 0.86$)$ \\
\hline $1993(n=660)$ & 13.4 & $0.35(0.32$ to 0.40$)$ & $0.90(0.74$ to 1.09$)$ & $1.98(1.61$ to 2.43$)$ & $2.87(2.33$ to 3.53$)$ & $0.66(0.57$ to 0.78$)$ \\
\hline $1994(n=1128)$ & 13.4 & $0.28(0.25$ to 0.32$)$ & $0.87(0.73$ to 1.03$)$ & $1.80(1.49$ to 2.19$)$ & $2.88(2.37$ to 3.50$)$ & $0.58(0.54$ to 0.63$)$ \\
\hline $1996(n=593)$ & 13.4 & $0.28(0.24$ to 0.33$)$ & $0.71(0.56$ to 0.90$)$ & $1.47(1.16$ to 1.86$)$ & $2.25(1.72$ to 2.96$)$ & $0.56(0.51$ to 0.63$)$ \\
\hline $1998(n=992)$ & 13.9 & NA & NA & NA & NA & $0.52(0.43$ to 0.62$)$ \\
\hline
\end{tabular}

NA=not available. 
to the increased restrictions on smoking in public places. There is little evidence that parents who smoke have achieved meaningful reductions in their children's exposure through limiting when and where they smoke. Complete cessation remains the only option that can be firmly endorsed, not only for parents' own health but also for their children's.

We thank the Imperial Cancer Research Fund for its support for the Nicotine Laboratory at the Medical Toxicology Unit, and Iain Carey for help with statistical analyses

Contributors: MJJ initiated this study, collated and analysed the data, and drafted the paper. EG and $\mathrm{VH}$ were responsible for designing and carrying out the survey field work. $\mathrm{CF}$ and $\mathrm{AB}$ performed the cotinine assays. DGC contributed to the data analysis and to drafting the paper. MJJ is guarantor for this study. Funding: $\mathrm{MJJ}$ and $\mathrm{AB}$ are supported by the Imperial Cancer Research Fund.

Competing interests: None declared.

1 Cook DG, Strachan DP. Health effects of passive smoking-10: summary of effects of parental smoking on the respiratory health of children and implications for research. Thorax 1999;54:357-66.

2 US Centers for Disease Control and Prevention. State-specific prevalence of cigarette smoking among adults, and children's and adolescents' exposure to environmental tobacco smoke-United States, 1996. MMWR Morb Mortal Wkly Rep 1997;46:1038-43.

3 Eriksen W, Bruusgaard D. Smoking behaviour in young families. Do parents take practical measures to prevent passive smoking by the children? Scand J Prim Health Care 1995;13:275-80.

4 Jaakkola N, Ruotsalainen R, Jaakkola JJ. What are the determinants of children's exposure to environmental tobacco smoke at home? Scand J Soc Med 1994:29:107-12.

5 Borland R, Mullins R, Trotter L, White V. Trends in environmental tobacco smoke restrictions in the home in Victoria, Australia. Tobacco Control 1999;8:266-71

6 Goddard E. Smoking among secondary schoolchildren in England in 1988. London: HMSO, 1989

7 Lader D, Matheson J. Smoking among secondary schoolchildren in 1990. London: HMSO, 1991.

8 Thomas M, Holroyd S, Goddard E. Smoking among secondary schoolchildren in 1992. London: HMSO, 1993

\section{What is already known on this topic}

Over the past decade smoking bans in public places have grown

It is not known whether smoking parents have avoided smoking in the home to protect their children

\section{What this study adds}

Cotinine concentrations in non-smoking children in Britain have almost halved from 1988 to 1998

This reduction is accounted for mainly by reductions in exposure in children from non-smoking homes and from a fall in the percentage of parents smoking

9 Bolling K. Smoking among secondary schoolchildren in 1993. London: HMSO, 1994.

10 Diamond A, Goddard E. Smoking among secondary schoolchildren in 1994. London: HMSO, 1995.

11 Jarvis L. Smoking among secondary school children in 1996: England. London: Stationery Office, 1997.

12 Goddard E, Higgins V. Smoking, drinking and drug use among young teenagers in 1998. Vol 1. England. London: Stationery Office, 1999.

13 McNeill AD, Jarvis MJ, West R, Russell MAH, Bryant A. Saliva cotinine as an indicator of cigarette smoking in adolescents. $\mathrm{Br} J$ Addict 1987:82:1355-60.

14 Feyerabend C, Russell MAH. A rapid gas-liquid chromatographic method for the determination of cotinine and nicotine in biological fluids. J Pharm Pharmacol 1990;42:450-2.

15 Thomas M, Walker A, Wilmot A, Bennett N. Living in Britain:results from the 1996 general household survey. London: Stationery Office, 1998.

16 Jarvis MJ, Strachan DP, Feyerabend C. Determinants of passive smoking in children in Edinburgh, Scotland. Am J Public Health 1992;82:1225-9.

17 Jarvis MJ, McNeill AD, Bryant A, Russell MA. Factors determining exposure to passive smoking in young adults living at home: quantitative analysis using saliva cotinine concentrations. Int J Epidemiol 1991;20: 26-31.

(Accepted 14 June 2000)

\section{Decreasing prevalence of cigarette smoking in the middle income country of Mauritius: questionnaire survey}

Helen S Cox, Joanne W Williams, Maximilian P de Courten, Pierrot Chitson, Jaakko Tuomilehto, Paul Z Zimmet

\begin{abstract}
Objectives To describe changes in the prevalence of cigarette smoking in the middle income country of Mauritius from 1987 to 1998 , and to relate these changes to legislative and health promotion efforts over the same period.

Design Questionnaire survey.

Setting Mauritius, an island in the Indian Ocean with a population of about 1.2 million (about $70 \%$ south Asian, 2\% Chinese, and 28\% Creole).

Participants Data were obtained from 5072 participants in 1987, 6573 in 1992, and 6281 in 1998. Main outcome measures Prevalence of current smoking in 1987, 1992, and 1998, sales of cigarettes in Mauritius, and information on activities for control of tobacco.

Results Self reported cigarette smoking has been decreasing in Mauritius since 1987, with the largest decrease between 1987 and 1992. From 1987 to 1998
\end{abstract}

smoking prevalence decreased by $23 \%$ in men and $61 \%$ in women. Smoking decreased across all age and ethnic groups and across different levels of income and education. Sales of cigarettes also decreased in line with smoking prevalence.

Conclusions The introduction of cigarette taxes, a limited health promotion programme, and the absence of massive promotional campaigns by the sole tobacco company on Mauritius have led to a striking and continued decrease in smoking prevalence and cigarette consumption on the island.

\section{Introduction}

Over the past few decades rates of cigarette smoking have decreased in developed countries following considerable legislative controls on tobacco sales and on advertising and with health promotion efforts. ${ }^{12}$ In contrast, smoking rates have increased in many low and middle income countries as tobacco companies
International

Diabetes Institute Caulfield 3162, Australia

Helen S Cox epidemiologist Joanne W Williams epidemiologist

Maximilian P de Courten

director of research Paul Z Zimmet professor

Non-Communicable Disease Unit, Ministry of Health and Quality of Life Mauritius

Pierrot Chitson director continued over

BMJ 2000;321:345-9 